\title{
Effects of insulin glargine versus metformin on glycemic variability, microvascular and beta-cell function in early type 2 diabetes
}

\author{
F. Pistrosch $\cdot$ C. Köhler $\cdot$ F. Schaper • \\ W. Landgraf $\cdot$ T. Forst $\cdot$ M. Hanefeld
}

Received: 4 September 2012/Accepted: 19 December 2012/Published online: 21 February 2013

(C) Springer-Verlag Italia 2013

\begin{abstract}
We investigated whether basal insulin as firstline treatment in recently diagnosed type 2 diabetes (T2D) can improve glucose control, microvascular function and preserve insulin secretion in comparison with metformin (MET). In this open-label, randomized, prospective 36-week study, 75 patients $(44 \mathrm{~m}, 31 \mathrm{f}$, mean age $60.7 \pm 9.2$ year) were allocated to treatment with either MET 1,000 mg b.i.d. $(n=36)$ or insulin glargine (GLA) at bedtime $(n=39)$. At baseline and study end, we performed a continuous glucose monitoring for assessment of interstitial glucose (IG) and measured microvascular function using Laser-Doppler fluxmetry. GLA versus MET treatment resulted in a more pronounced reduction in FPG $(\Delta: 3.1 \pm 2.5$ vs. $1.4 \pm 1.5 \mathrm{mmol} / \mathrm{l} ; p<0.001)$ and overall IG ( $\Delta$ AUC. $671 \pm 507$ vs. $416 \pm 537 \mathrm{mmol} / \mathrm{l} \mathrm{min} ; p=0.04)$. Postprandial PG and IG differences after a standardized test meal did not reach significance. Proinsulin/C-peptide and HOMA
\end{abstract}

Communicated by Antonio Secchi.

F. Pistrosch · C. Köhler · F. Schaper · M. Hanefeld

Study Centre Prof. Hanefeld, GWT, Technical University

Dresden, Dresden, Germany

F. Pistrosch - W. Landgraf

Clinic for Internal Medicine III, University Hospital Dresden,

Dresden, Germany

F. Pistrosch ( $\square)$

Medizinische Klinik III, Technical University Dresden,

Fiedlerstrasse 34, 01307 Dresden, Germany

e-mail: frankpistrosch@hotmail.com

W. Landgraf

Sanofi-Aventis, Frankfurt, Germany

T. Forst

IKFE GmbH, Mainz, Germany
B as marker of endogenous insulin secretion were significantly more improved by GLA. Microvascular blood flow improved only in MET-treated patients. Early basal insulin treatment with GLA in T2D patients provided a better control of FPG, overall IG load and biomarker of beta-cell function compared to the standard treatment with MET. MET treatment resulted in an improvement of microvascular function. Studies of longer duration are needed to evaluate the durability of glucose control and $\beta$ cell protection with early GLA treatment.

Keywords Insulin glargine $\cdot$ Continuous glucose monitoring $\cdot$ CGM $\cdot$ Laser-doppler $\cdot$ Beta-cell

\section{Introduction}

Type 2 diabetes mellitus is characterized by an impaired insulin secretion in response to glucose stimulation [1]. With ongoing disease duration, most patients show a progressive reduction in $\beta$-cell mass and deterioration in beta-cell function [2, 3]. Current treatment guidelines recommend the introduction of metformin at diagnosis in combination with diet and exercise as first-line therapy for type 2 diabetes [4]. However, metformin does not prevent progression of type 2 diabetes over long term as consistently shown by the UK prospective diabetes study (UK-PDS) or a diabetes outcome progression trial (ADOPT) $[5,6]$. Chronic hyperglycemia has harmful effects on glucoseinduced insulin secretion and might accelerate apoptosis of $\beta$-cells [7]. Furthermore, chronic hyperglycemia can deteriorate endothelial function [8]. This glucotoxic effect became apparent if blood glucose concentration exceeds $6.4 \mathrm{mmol} / \mathrm{l}$ and is primarily associated with a deterioration of pulsatile insulin secretion and acute insulin response to a 
glucose load [7]. Insulin therapy according to guidelines is usually introduced late in the course of the disease [4]. However, recently published trials have demonstrated a sustained improvement of endogenous insulin secretion by early short-term exogenous insulin supplementation $[9,10]$. In addition, an outcome trial with basal insulin glargine compared to standard care demonstrated a significant reduction in incident type 2 diabetes by $28 \%$ in insulin-treated participants without diabetes at baseline [11]. These results suggest that strict glucose control with early insulin treatment may protect $\beta$-cells from harmful effects of glucotoxicity. Long acting insulin analogs provide good glycemic control together with a low risk of hypoglycemia [12]. The initiation of basal insulin treatment early in the course of the disease may help to minimize the required insulin dosage and therefore adverse effects on body weight [13]. In contrast to metformin which cannot be used in several patients, for example, with advanced renal impairment, basal insulin may be used regardless of concomitant diseases [14].

The aim of our study was to evaluate the effects of basal insulin glargine in patients with drug naïve type 2 diabetes ( $<5$ years) on quality of glucose control as well as on betacell function and microvascular blood flow in comparison with metformin.

\section{Materials and methods}

Study protocol and patients

Ninety-six patients were included into this multicenter, open-label, prospective study to receive either metformin at a target dose of 1,000 mg b.i.d. or insulin glargine once-daily at bedtime. Insulin dose was titrated stepwise to a target fasting glucose of $\leq 5.6 \mathrm{mmol} / \mathrm{l}$ according to a standardized titration schedule [15]. All insulin-treated patients were instructed to assess their fasting blood glucose daily using the FreeStyle Lite ${ }^{\circledR}$ (Abbott, Wiesbaden, Germany) and to adjust their insulin dose to target. In addition, all patients were asked to self-assess blood glucose if they experienced clinical symptoms of hypoglycemia.

Main inclusion criteria for the study were a drug naïve type 2 diabetes mellitus with $<5$ years after diagnosis and a $\mathrm{HbA1c}$ between 6.5 and $8 \%$. Main exclusion criteria were renal dysfunction with a calculated glomerular filtration rate below $60 \mathrm{ml} / \mathrm{min}$, acute or chronic diseases which could lead to tissue hypoxia, the use of intravascular contrast agents throughout the study, increase in serum transaminases more than 2.5-fold of the upper limit of the normal range, or systemic corticosteroid treatment. At baseline and after 36 weeks of treatment, all patients received a $72 \mathrm{~h}$ continuous interstitial glucose monitoring
(CGM) with a standardized test meal at day 2 and a test of microvascular blood flow. All patients got a reinforcement of dietary counseling at study entry and throughout the study. Dietary records of the patients were analyzed by specialized staff at each visit date to prevent weight gain. The study protocol was approved by the ethics committee of the Saxony chamber of physicians. All patients gave written informed consent before inclusion.

\section{Continuous glucose monitoring}

We used the Medtronic System Gold ${ }^{\mathrm{TM}}$ Monitor with MiniMed glucose subcutaneous sensors (Medtronic MiniMed, Northridge, CA). The system is approved for a continuous measurement of interstitial glucose (IG) every 5 min over $72 \mathrm{~h}$ within the subcutaneous fat tissue. Analysis was limited to the data obtained from the intermediate $48 \mathrm{~h}$ of recording to avoid bias due to insertion and removal of the CGM. On the morning of the second day of CGM, a standardized test meal was consumed by the patients at the study site. The test meal consisted of $95 \mathrm{~g}$ whole-grain bread, $20 \mathrm{~g}$ margarine, $25 \mathrm{~g}$ jam, $25 \mathrm{~g}$ cheese, $200 \mathrm{ml}$ orange juice, and $200 \mathrm{ml}$ milk mix drink which corresponds to $50 \%$ carbohydrates, $35 \%$ fat, and $15 \%$ proteins with a total energy content of $511 \mathrm{kcal}$.

For the assessment of glycemic variability, we calculated the overall area under the IG curve (AUC) and the incremental area under the glucose curve of the test meal (incAUC) and assessed the mean IG, standard deviation (SD) of IG, and mean average glucose excursions (MAGE). MAGE was calculated as the arithmetic mean of the differences between consecutive peaks and nadirs, provided that the differences are greater than one SD of the mean glucose value.

\section{Laser-Doppler measurement of microcirculation}

Microvascular skin blood flow has been assessed using Laser-Doppler fluxmetry (O2C, LEA Medizintechnik, Giessen, Germany) as described [16]. The skin probe was placed at the dorsal thenar site of the left hand in between the phalanx of the thumb and metatarsal bone of the 2nd digit. Measurements were performed at $2 \mathrm{~mm}$ depth with a continuously emitted laser light (wavelength $830 \mathrm{~nm}$ ). The movement of erythrocytes within the sample volume causes a Doppler shift effect of the laser light which allows for the calculation of the flow velocity and consequently the relative blood flow, which is expressed in arbitrary units (U). We measured the pre-ischemic blood flow (pBF) and the maximal post-ischemic blood flow (maxBF) during reactive hyperemia after 5 min of suprasystolic ischemia of the forearm. Average pBF was calculated over $4 \mathrm{~min}$ and maxBF was recorded as peak blood flow 20-40 s after cuff 
release. The same location of the skin probe was used for repeated measurements; patients rested at least $30 \mathrm{~min}$ in a quite temperature-controlled room prior to the start of the examination.

\section{Biochemical analysis}

HbA1c was measured chromatographically using HPLC (TOSOH G8, Stuttgart, Germany); insulin, proinsulin, and C-peptide were measured with EIA (TOSOH AIA 360, Stuttgart, Germany); triglycerides were measured with the GPO-PAP method; LDL and HDL cholesterol fractions were measured by enzymatic tests on the Konelab 20xTi (ThermoFisher, Dreieich, Germany).

Homeostasis model assessment was used to estimate basal beta-cell function (HOMA B) and insulin resistance (HOMA IR). HOMA B was calculated as $20 \times$ fasting insulin/(fasting plasma glucose - 3.5) and HOMA IR as fasting plasma glucose $\times$ fasting insulin/22.5.

\section{Statistical analysis}

All continuous parameters are expressed as mean \pm SD if not indicated otherwise. Not normally distributed variables were log-transformed. Student's $t$ test for comparisons between treatment groups and paired $t$ test for comparisons within a treatment group (i.e., first vs. last visit) were applied. The primary objective was the change of IGAUC, and therefore, we performed a per protocol analysis. The calculated power for the primary objective was $78 \%$. Not normally distributed variables were analyzed using Mann-Whitney $U$ test. Categorical variables were compared by chi square test. Differences of baseline variables between study groups were considered using an analysis of covariates (ANCOVA) for the evaluation of treatment effects. A $p$ value $<0.05$ indicated statistical significant differences. All statistical analyses were performed using SPSS 19.0 software.

\section{Results}

Seventy-five out of 97 randomized patients finished the study per protocol. The dropout rate was identical between metformin $(n=5)$ - and glargine $(n=6)$-treated patients. In 11 patients, CGM at the end of study could not be analyzed due to recording problems.

Baseline clinical parameters were well balanced between treatment groups (Table 1). Interstitial glucose monitoring demonstrated a more pronounced reduction in mean IG and AUC with insulin glargine, whereas the reduction in the incremental AUC was comparable between treatments (Table 2). However, after 36 weeks of
Table 1 Baseline clinical parameters

\begin{tabular}{llll}
\hline & $\begin{array}{l}\text { Metformin } \\
(n=36)\end{array}$ & $\begin{array}{l}\text { Insulin } \\
(n=39)\end{array}$ & $p$ \\
\hline Sex female n (\%) & $18(50)$ & $13(33.3)$ & 0.220 \\
Age (year) & $62.03 \pm 9.4$ & $60 \pm 9.3$ & 0.348 \\
$\begin{array}{l}\text { Diabetes duration } \\
\quad \text { year) }\end{array}$ & $2.6 \pm 1.6$ & $2.8 \pm 1.4$ & 0.602 \\
BMI $\left(\mathrm{kg} / \mathrm{m}^{2}\right)$ & $29.9 \pm 5.3$ & $29.2 \pm 4.6$ & 0.537 \\
Weight $(\mathrm{kg})$ & $87.6 \pm 17.9$ & $87.6 \pm 15.1$ & 0.965 \\
Waist $(\mathrm{cm})$ & $102.5 \pm 14.5$ & $103.7 \pm 11.1$ & 0.678 \\
Systolic BP (Torr) & $141.5 \pm 14.8$ & $141 \pm 15.7$ & 0.896 \\
Diastolic BP (Torr) & $81.2 \pm 10.4$ & $85.3 \pm 9.8$ & 0.133 \\
\hline
\end{tabular}

treatment, we found nearly identical IG curves (Fig. 1) for insulin and metformin. Glycemic variability (expressed as MAGE or SD) at the study end was significantly higher with insulin glargine; however, the change from baseline was at the same range for both indices (Table 2).

Insulin glargine treatment primarily reduced fasting hyperglycemia with first significant difference of FPG occurring after 8 weeks, mainly as an effect of stepwise insulin titration, and FPG remained significantly different between treatments until end of study (Fig. 2a). However, the between group difference did not reach significance level for change of $\mathrm{HbA} 1 \mathrm{c}$ or PPG $2 \mathrm{~h}$ after the test meal (Table 2) which was in agreement with the IG parameter (Fig. 1). Proinsulin as a marker of $\beta$-cell dysfunction was significantly reduced by both treatments. Of notice, this reduction was more pronounced in the glargine-treated patients in the fasting and postprandial state (Table 2). Due to insulin supplementation, fasting endogenous insulin secretion (assessed by C-peptide concentration) was decreased in the glargine group, whereas postprandial endogenous insulin secretion was preserved (Table 2). Consequently, the HOMA B (Table 2) as well as proinsulin/C-peptide ratio after the test meal (Fig. 3) as marker of endogenous insulin secretion and therefore beta-cell function were significantly more improved by insulin glargine.

Microvascular blood flow after 36 weeks of treatment was identical with insulin and metformin. However, the post-ischemic microvascular response improved in metformin-treated patients but not in insulin-treated patients (Table 2).

Despite intensive dietary counseling, glargine-treated patients gained weight (Fig. 2b) associated with a significant increase in waist circumference of $1.1 \pm 3.7 \mathrm{~cm}$ versus a decrease of $1.9 \pm 4.1 \mathrm{~cm}$ in the metformin group $(p<0.001)$.

The mean insulin dose at study end was $25.9 \pm 13.2 \mathrm{U}$ $(0.3 \pm 0.1 \mathrm{U} / \mathrm{kg}$ body weight $)$.

Hypoglycemic episodes during BG self-monitoringdefined as any $\mathrm{BG}$ value $<3.1 \mathrm{mmol} / \mathrm{l}$ or symptoms of 
Table 2 Glycemic parameter assessed by continuous glucose monitoring, biomarker of beta-cell function and biochemical parameter

\begin{tabular}{|c|c|c|c|}
\hline & Metformin $(n=36)$ & Insulin glargine $(n=39)$ & $p$ \\
\hline \multicolumn{4}{|l|}{ Parameter of glucose control } \\
\hline FPG baseline (mmol/l) & $8.7 \pm 1.6$ & $9.2 \pm 2.1$ & 0.297 \\
\hline FPG week $36(\mathrm{mmol} / \mathrm{l})$ & $7.2 \pm 1$ & $6.1 \pm 1.1$ & 0.001 \\
\hline FPG change (mmol/l) & $-1.4 \pm 1.5$ & $-3.1 \pm 2.5$ & 0.001 \\
\hline PPG $120^{\prime}$ baseline $(\mathrm{mmol} / \mathrm{l})$ & $10.3 \pm 2.8$ & $11.1 \pm 4.5$ & 0.415 \\
\hline PPG $120^{\prime}$ week $36(\mathrm{mmol} / \mathrm{l})$ & $8.4 \pm 2.1$ & $8.3 \pm 2.5$ & 0.832 \\
\hline PPG $120^{\prime}$ change $(\mathrm{mmol} / \mathrm{l})$ & $-1.6 \pm 2.5$ & $-2.8 \pm 3.2$ & 0.106 \\
\hline HbA1c baseline $(\%)$ & $6.9 \pm 0.4$ & $7.2 \pm 0.7$ & 0.045 \\
\hline HbA1c week $36(\%)$ & $6.31 \pm 0.4$ & $6.36 \pm 0.4$ & 0.478 \\
\hline HbA1c change $(\%)$ & $-0.6 \pm 0.41$ & $-0.8 \pm 0.69$ & 0.087 \\
\hline \multicolumn{4}{|l|}{ Interstitial glucose measurements } \\
\hline AUC baseline (mmol $\left.1^{-1} \mathrm{~min}\right)$ & $2387.0 \pm 500.3$ & $2671.5 \pm 598.5$ & 0.029 \\
\hline AUC week $36\left(\mathrm{mmol} \mathrm{l}^{-1} \mathrm{~min}\right)$ & $1971.8 \pm 337.8$ & $2000.3 \pm 313.1$ & 0.774 \\
\hline AUC change $\left(\mathrm{mmol}^{-1} \mathrm{~min}\right)$ & $-416.1 \pm 537.6$ & $-671.2 \pm 507.9$ & 0.039 \\
\hline incAUC baseline $\left(\mathrm{mmol}^{-1} \mathrm{~min}\right)$ & $55.4 \pm 30.2$ & $73.9 \pm 39.9$ & 0.027 \\
\hline incAUC week $36\left(\mathrm{mmol} \mathrm{l}^{-1} \mathrm{~min}\right)$ & $49.6 \pm 25.0$ & $68.3 \pm 24.6$ & 0.002 \\
\hline incAUC change $\left(\mathrm{mmol}^{-1} \mathrm{~min}\right)$ & $-5.8 \pm 31.8$ & $-5.7 \pm 40.4$ & 0.989 \\
\hline Mean IG baseline (mmol/l) & $8.3 \pm 1.7$ & $9.4 \pm 2.1$ & 0.015 \\
\hline Mean IG week 36 (mmol/l) & $6.9 \pm 1.2$ & $7.0 \pm 1.0$ & 0.573 \\
\hline Mean IG change (mmol/l) & $-1.4 \pm 1.8$ & $-2.4 \pm 1.7$ & 0.022 \\
\hline MAGE baseline & $3.3 \pm 0.9$ & $4.0 \pm 1.1$ & 0.001 \\
\hline MAGE week 36 & $2.9 \pm 1.1$ & $3.7 \pm 1.0$ & 0.001 \\
\hline MAGE change & $-0.4 \pm 1.7$ & $-0.3 \pm 1.3$ & 0.676 \\
\hline SD baseline & $1.6 \pm 0.8$ & $1.8 \pm 0.6$ & 0.121 \\
\hline SD week 36 & $1.3 \pm 0.5$ & $1.7 \pm 0.5$ & 0.001 \\
\hline SD change & $-0.2 \pm 0.7$ & $-0.07 \pm 0.7$ & 0.45 \\
\hline \multicolumn{4}{|l|}{ Parameter of beta-cell function } \\
\hline Proinsulin $0^{\prime}$ baseline $(\mathrm{pmol} / \mathrm{l})$ & $8.6 \pm 6.2$ & $13.0 \pm 13.5$ & 0.023 \\
\hline Proinsulin $0^{\prime}$ wk 36 (pmol/l) & $5.8 \pm 4.6$ & $5.4 \pm 5.0$ & 0.35 \\
\hline Proinsulin $0^{\prime}$ change (pmol/l) & $-3 \pm 4.1$ & $-7.6 \pm 10.8$ & 0.001 \\
\hline Proinsulin $120^{\prime}$ baseline $(\mathrm{pmol} / \mathrm{l})$ & $26.8 \pm 16.0$ & $37.8 \pm 32.2$ & 0.069 \\
\hline Proinsulin $120^{\prime}$ week $36(\mathrm{pmol} / \mathrm{l})$ & $20.4 \pm 19.9$ & $26.8 \pm 29$ & 0.259 \\
\hline Proinsulin $120^{\prime}$ change (pmol/1) & $-6.6 \pm 14.3$ & $-11.1 \pm 26.8$ & 0.019 \\
\hline C-peptide $0^{\prime}$ baseline $(\mathrm{nmol} / \mathrm{l})$ & $1.0 \pm 0.5$ & $0.9 \pm 0.4$ & 0.453 \\
\hline C-peptide $0^{\prime}$ week $36(\mathrm{nmol} / \mathrm{l})$ & $0.9 \pm 0.4$ & $0.5 \pm 0.3$ & 0.001 \\
\hline C-peptide $0^{\prime}$ change $(\mathrm{nmol} / \mathrm{l})$ & $-0.1 \pm 0.3$ & $-0.4 \pm 0.4$ & 0.001 \\
\hline C-peptide $120^{\prime}$ baseline $(\mathrm{nmol} / \mathrm{l})$ & $2.7 \pm 1.1$ & $2.4 \pm 1.0$ & 0.274 \\
\hline C-peptide $120^{\prime}$ week $36(\mathrm{nmol} / \mathrm{l})$ & $2.6 \pm 1.3$ & $2.2 \pm 1.0$ & 0.274 \\
\hline C-peptide $120^{\prime}$ change (nmol/l) & $0 \pm 0.7$ & $-0.2 \pm 0.8$ & 0.348 \\
\hline Insulin $0^{\prime}$ baseline $(\mathrm{pmol} / \mathrm{l})$ & $90.6 \pm 51.2$ & $85.1 \pm 48.6$ & 0.733 \\
\hline Insulin $0^{\prime}$ week $36(\mathrm{pmol} / \mathrm{l})$ & $71.6 \pm 43.0$ & $104.4 \pm 62.9$ & 0.01 \\
\hline Insulin $0^{\prime}$ change $(\mathrm{pmol} / \mathrm{l})$ & $-19.2 \pm 26.0$ & $19.2 \pm 47.9$ & 0.001 \\
\hline Insulin $120^{\prime}$ baseline $(\mathrm{pmol} / \mathrm{l})$ & $445.2 \pm 303$ & $401.8 \pm 296.2$ & 0.487 \\
\hline Insulin $120^{\prime}$ week $36(\mathrm{pmol} / \mathrm{l})$ & $364.6 \pm 285$ & $448.8 \pm 371.9$ & 0.416 \\
\hline Insulin $120^{\prime}$ change $(\mathrm{pmol} / \mathrm{l})$ & $-79.9 \pm 216.9$ & $46.6 \pm 275.6$ & 0.06 \\
\hline Insulin/proinsulin $120^{\prime}$ baseline & $22.2 \pm 29.1$ & $12.5 \pm 7.5$ & 0.063 \\
\hline Insulin/proinsulin $120^{\prime}$ week 36 & $24.7 \pm 27.1$ & $20.7 \pm 11.8$ & 0.410 \\
\hline Insulin/proinsulin $120^{\prime}$ change & $3.0 \pm 8.4$ & $8.2 \pm 9.4$ & 0.015 \\
\hline
\end{tabular}


Table 2 continued

\begin{tabular}{|c|c|c|c|}
\hline & $\operatorname{Metformin}(n=36)$ & Insulin glargine $(n=39)$ & $p$ \\
\hline HOMA B baseline & $49.4 \pm 34.5$ & $48.2 \pm 36.7$ & 0.893 \\
\hline HOMA B week 36 & $56.3 \pm 34.5$ & $128 \pm 99$ & 0.001 \\
\hline HOMA B change & $4.4 \pm 19.5$ & $77.2 \pm 97.8$ & 0.001 \\
\hline HOMA IR baseline & $5.0 \pm 3.7$ & $4.9 \pm 3.8$ & 0.893 \\
\hline HOMA IR week 36 & $3.2 \pm 2.0$ & $4.0 \pm 2.4$ & 0.116 \\
\hline HOMA IR change & $-1.8 \pm 1.8$ & $-1.1 \pm 3.0$ & 0.239 \\
\hline \multicolumn{4}{|l|}{ Blood flow measurements } \\
\hline Pre-ischemic BF baseline (U) & $23.3 \pm 13.4$ & $25.8 \pm 14.7$ & 0.350 \\
\hline Pre-ischemic BF week $36(\mathrm{U})$ & $25.2 \pm 13.4$ & $26.6 \pm 14.7$ & 0.766 \\
\hline MaxBF baseline (U) & $81.9 \pm 48$ & $99.0 \pm 29.1$ & 0.091 \\
\hline MaxBF week $36(\mathrm{U})$ & $90.7 \pm 43$ & $89.1 \pm 32.4$ & 0.697 \\
\hline MaxBF change (U) & $8.8 \pm 31.5$ & $-9.9 \pm 39.6$ & 0.042 \\
\hline \multicolumn{4}{|l|}{ Safety parameter } \\
\hline Duration glucose $<3.9$ baseline (min) & $1.5 \pm 9.2$ & $3.0 \pm 13.1$ & 0.592 \\
\hline Duration glucose $<3.9$ week 36 (min) & $11.2 \pm 41.4$ & $13.6 \pm 46.5$ & 0.468 \\
\hline Self assessed BG $<3.1 \mathrm{mmol} / \mathrm{l}(n)$ & 4 & 14 & 0.045 \\
\hline Gastrointestinal complaints $(n)$ & 10 & 0 & 0.001 \\
\hline
\end{tabular}

$A U C$ area under the interstitial glucose curve, incAUC incremental area under the interstitial glucose curve of the test meal, Mean $I G$ mean interstitial glucose values, $S D$ standard deviation of interstitial glucose, $M A G E$ mean average glucose excursions, proinsulin (pmol/l); C-peptide $(\mathrm{nmol} / \mathrm{l})$; insulin (pmol/l), $O^{\prime}$ start of the test meal, $120^{\prime} 2 \mathrm{~h}$ after the test meal; change displayed difference between week 36 and baseline, $F P G$ fasting plasma glucose, $P P G$ postprandial plasma glucose, $B F$ blood flow, $B G$ blood glucose

Fig. 1 Mean interstitial glucose values of the second day (including a standardized breakfast) after 36 weeks of treatment with insulin glargine or metformin

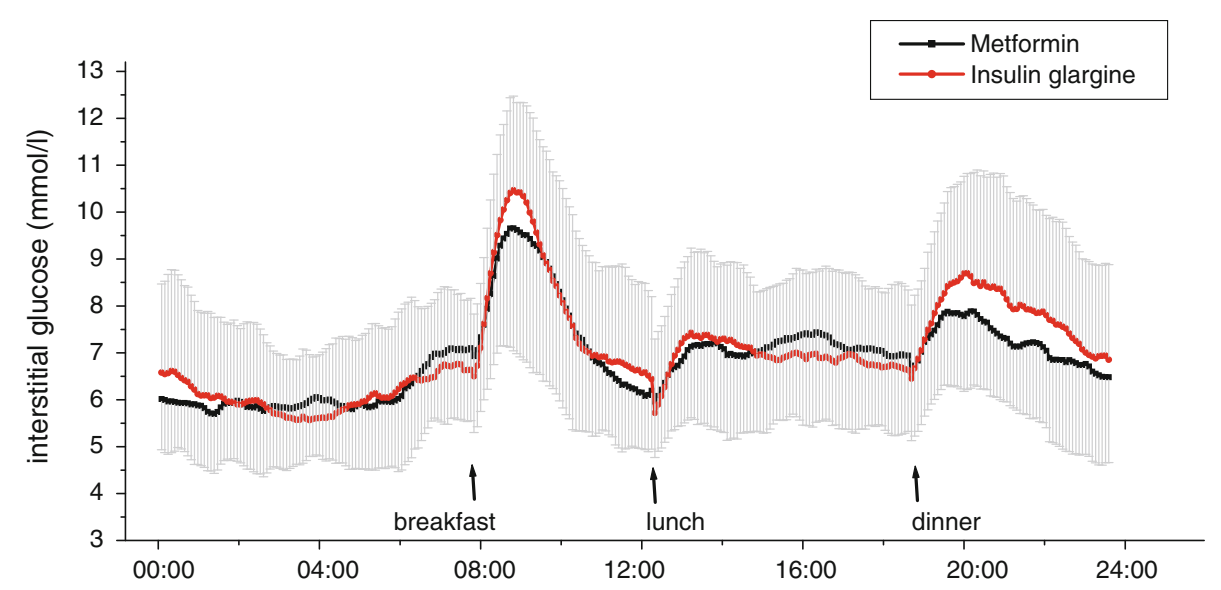

hypoglycemia-occurred rarely and were more often reported in insulin-treated patients (Table 2). The mean duration of IG episodes $<3.9 \mathrm{mmol} / 1$ during CGM was similar between treatment groups (Table 2). There was no severe hypoglycemia and only one symptomatic hypoglycemia reported in the glargine group during the study. Main adverse events in metformin-treated patients were gastrointestinal complaints, that is, discomfort, flatulence, and diarrhea (Table 2). However, despite such undesired side effects of metformin, most of the patients which completed the study received the target dose of 2,000 $\mathrm{mg}$ metformin per day (mean dose at end of study $1,883 \pm 357 \mathrm{mg}$ ).

\section{Discussion}

For the first time, our study investigated the effects of basal insulin versus metformin on glycemic control, beta-cell function, and microvascular blood flow when used as firstline treatment of type 2 diabetes. In contrast to other studies of rather short duration with various regimes of insulin application [9, 10, 17, 18], the present prospective randomized trial allowed us to compare the effects of different treatments on beta-cell function and blood flow at the same level of HbA1c and hence chronic hyperglycemia. Furthermore, all patients were drug naïve with an 

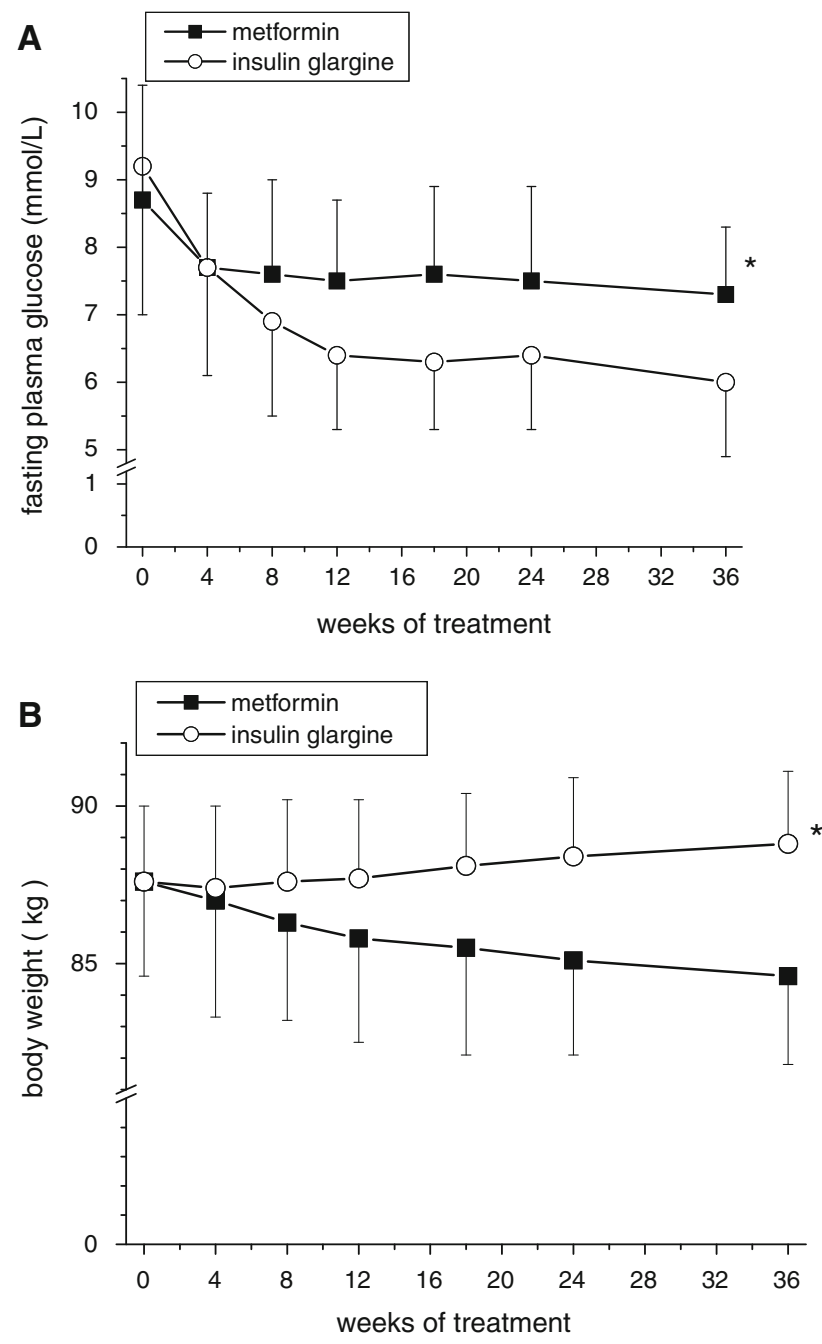

Fig. 2 Time course of fasting plasma glucose concentration (a) and body weight (b). Data expressed as mean \pm SD. ${ }^{*} p<0.01$ (ANOVA for repeated measures)

acceptable $\mathrm{HbA} 1 \mathrm{c}(<8.5 \%)$ and thus presumably enough $\beta$-cell mass for improvement of beta-cell function if harmful effects of glucotoxicity can be reduced by near to normal glucose control.

As expected, we found a significantly improved control of overall interstitial glucose and FPG in both groups but insulin glargine treatment resulted in significantly lower FPG compared to metformin (Fig. 2a). We also found a more pronounced improvement of basal and postprandial beta-cell function expressed by the basal ratio of HOMA B/HOMA IR (Fig. 3a) and postprandial proinsulin/C-peptide ratio (Fig. 3b) in insulin-treated patients. However, despite these more pronounced effects on FPG and betacell function, we did not find a significant difference of postprandial or overall interstitial glucose load and HbA1c with insulin glargine compared to metformin at study end (Fig. 1). These results are in agreement with data from the

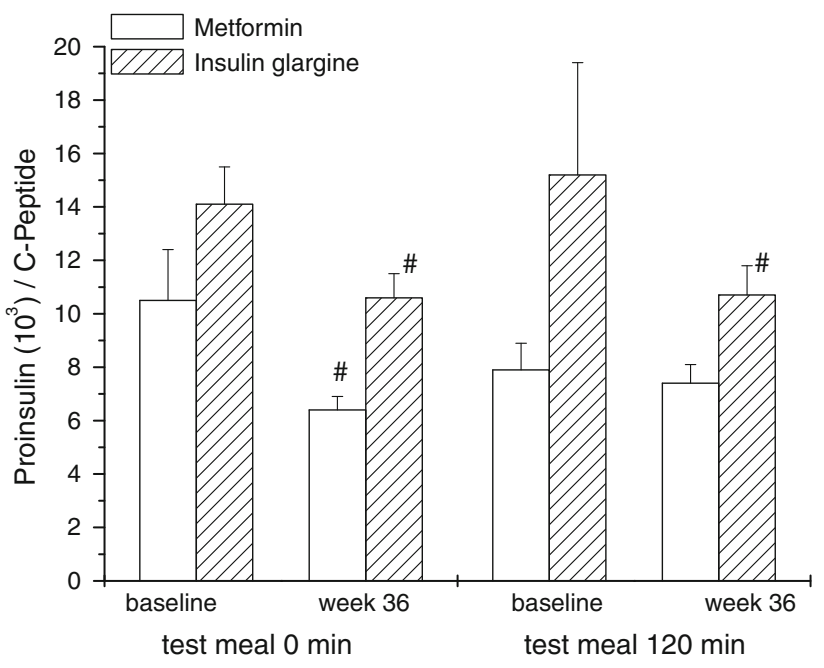

Fig. 3 Fasting (0 min) and postprandial (120 min) beta-cell function assessed by proinsulin/C-peptide at baseline and study end (week 36), ${ }^{\#} p<0.05$ vs. baseline value. Data are expressed as mean \pm SEM

recently published Outcome Reduction with an Initial Glargine Intervention (ORIGIN) that demonstrated a more pronounced effect of insulin glargine on FPG than on HbA1c compared to standard care [11]. One possible explanation for similar effects of insulin glargine on quality of glucose control compared to metformin in the present study could be the differences in body weight gain, visceral obesity, and insulin resistance after 36 weeks of treatment. The improvement of endogenous insulin secretion after insulin treatment did not completely outweigh insulin resistance as demonstrated by insulin and plasma glucose values $2 \mathrm{~h}$ after the test meal.

A previous study by Alvarsson et al. [19] investigated the effects of insulin treatment on stimulated C-peptide secretion in comparison with sulfonylurea over a 2-year period. The authors reported an increase in stimulated C-peptide response after insulin treatment and a decreased response after sulfonylurea. This was accompanied by a significantly lower HbA1c value after 2 years in insulintreated patients. However, these patients had a comparable weight gain throughout the study and similar degree of insulin resistance [19].

It might be possible that the improvement of beta-cell function due to insulin treatment will significantly affect progression of type 2 diabetes as demonstrated by Weng and colleagues [10]. The concept of $\beta$-cell recovery due to basal insulin supplementation has been developed several years ago [20]. Intermittent inhibition of endogenous insulin secretion by somatostatin has been demonstrated to increase the subsequent glucose-induced insulin secretion [21]. A reduction in chronic hyperglycemia by exogenous insulin supplementation might be equally effective as demonstrated in recent trials $[10,18]$. The latter effect can 
be explained by a suppression of hyperglycemia-induced reactive oxygen species $[22,23]$ or anti-apoptotic actions of insulin itself [24].

We found a reduction in the post-ischemic microvascular response in insulin-treated patients compared to baseline, whereas metformin increased the post-ischemic microvascular response and hence endothelial function (Table 2). Previous studies demonstrated an adversative vascular action of insulin in healthy individuals [25]: Insulin modulates endothelium-dependent vascular effects through two distinct intracellular pathways. While the physiological signaling of insulin in insulin-sensitive subjects is mediated through the phosphatidylinositol-3-kinase signaling pathway resulting in the release of nitric oxide (NO) and vasodilation, pathological signaling through the mitogenactivated-protein-kinase signaling pathway in insulinresistant subjects stimulates endothelin 1 release with subsequent vasoconstriction [26]. In addition, insulin was shown to stimulate sympathetic nerve outflow which might also counter the vasodilatory effects of NO-mediated vasodilation. Therefore, the resulting vascular action of insulin depends on the vascular bed and the degree of insulin resistance, for example, insulin eventually mediates vasodilatation of the muscular vasculature in healthy individuals [25]. Baseline skin blood flow is mainly regulated by sympathetic innervations and only to a lesser extent by vascular endothelium. However; post-ischemic skin blood flow is mediated by endothelium-dependent vasodilators especially prostaglandins [27]. It is still under debate whether skin blood flow is a reliable measure for general endothelial function and a surrogate parameter of cardiovascular endpoints. However, there are several studies which demonstrate a significant correlation between skin blood flow and other techniques for assessment of endothelial function [28], and there are interventional studies which demonstrate an improvement of skin blood flow after reduction in cardiovascular risk factors [16, 27]. Metformin treatment resulted in a significant reduction in body weight and an improvement of insulin sensitivity (Table 2), whereas insulin increased body weight and improved insulin resistance to a smaller extend than metformin. Since insulin resistance can deteriorate endothelium-dependent vasodilatation [29], it is conceivable that hyperinsulinemia in combination with a nearly unchanged insulin resistance in insulin glargine-treated patients increased the sympathetic nerve outflow without a compensatory activation of endothelium-dependent vasodilators. This finding is in agreement with previous studies which described an impaired insulin action on endothelium-dependent vasodilation in type 2 diabetic patients [30]. There are conflicting results about direct vascular effects of metformin treatment itself; however, several studies demonstrated an improvement of endothelial function [31, 32]. Furthermore, insulin-treated patients in the present study had significantly higher fluctuations of interstitial glucose-expressed as MAGE and SD (Table 2). Glucose fluctuations itself may contribute to the generation of oxidative stress and consequently to endothelial dysfunction [33-35].

Risk of hypoglycemia was not significantly increased with insulin despite $\mathrm{HbA} 1 \mathrm{c}<6.5 \%$ equal to metformin. Several trials using insulin even in the prediabetic state reported no relevant safety concerns about hypoglycemia and only moderately increased body weight $[11,17,36$, 37]. Our study confirmed the low risk of hypoglycemia of insulin glargine treatment by CGM recordings. The higher rate of self-monitored asymptomatic hypoglycemic events ( 8 vs. 2) might be biased due to the higher rate of glucose self-monitoring itself in the insulin glargine-treated patients.

A limitation of our study was the rather small sample size and the higher than expected range of interstitial glucose measurements and biochemical parameter. Therefore, we cannot exclude whether the lack of a statistical significant difference in some results was due to beta errors. A further limitation may be the higher than aimed FPG value in insulin-treated patients despite a differentiated titration regimen. Main reason for this finding was the day to day variation of self-monitored glucose values. In fact, nearly all patients achieved the target value of $5.6 \mathrm{mmol} / \mathrm{l}$ of blood glucose after a median of 8 week of treatment during the study. However, we observed day by day fluctuations of fasting glucose by $1.5 \mathrm{mmol} / \mathrm{l}$, which did not allow a further up-titration of insulin dose. A FPG at the target value might have resulted in even lower glucotoxicity and better postprandial glucose values as suggested by our previous study [36]. Furthermore, we did not found a significant correlation between FPG and incremental AUC and no significantly different PPG values between insulin-treated patients who reached the target PG of $5.6 \mathrm{mmol} / \mathrm{l}$ at week $36(n=15)$ and metformin-treated patients (data not shown). On the other hand, as demonstrated in Fig. 2, insulin-treated patients had significantly lower fasting plasma glucose than metformin-treated patients throughout the whole study period.

Do our results imply to initiate basal insulin treatment as first-line therapy of type 2 diabetes instead of metformin? The answer is no with regard to glycemic control and endothelial function since we reach the same level of postprandial or chronic hyperglycemia with both medications, and we have no improvement of microvascular endothelial function with insulin. The answer may possible yes with regard to beta-cell function since we know from a recently large randomized trial that insulin treatment might reduce the progression of type 2 diabetes [11]. 
Acknowledgments We thank Thomas Behnke, Studienzentrum Neuwied, and Mazin Sanuri, Diabetespraxis Essen, for their contribution to conduct this study. The study was funded by Sanofi-Aventis, Germany. Clinical Trials identifier: NCT00857870. FP received lecture fees from Sanofi-Aventis. MH serves as advisory board member of Sanofi-Aventis. WL is an employee of Sanofi-Aventis, Frankfurt, Germany.

Conflict of interest For all other authors no competing financial interests exist.

\section{References}

1. Ward WK, Bolgiano DC, McKnight B, Halter JB, Porte D Jr (1984) Diminished B cell secretory capacity in patients with noninsulin-dependent diabetes mellitus. J Clin Invest 74(4): $1318-1328$

2. Butler AE, Janson J, Bonner-Weir S, Ritzel R, Rizza RA, Butler PC (2003) Beta-cell deficit and increased beta-cell apoptosis in humans with type 2 diabetes. Diabetes 52(1):102-110

3. Kahn SE (2003) The relative contributions of insulin resistance and beta-cell dysfunction to the pathophysiology of Type 2 diabetes. Diabetologia 46(1):3-19

4. Nathan DM, Buse JB, Davidson MB, Ferrannini E, Holman RR, Sherwin R, Zinman B (2008) Management of hyperglycaemia in type 2 diabetes mellitus: a consensus algorithm for the initiation and adjustment of therapy. Update regarding the thiazolidinediones. Diabetologia 51(1):8-11

5. Kahn SE, Haffner SM, Heise MA, Herman WH, Holman RR, Jones NP, Kravitz BG, Lachin JM, O'Neill MC, Zinman B, Viberti G (2006) Glycemic durability of rosiglitazone, metformin, or glyburide monotherapy. N Engl J Med 355(23):2427-2443

6. UK Prospective Diabetes Study (UKPDS) Group (1998) Effect of intensive blood-glucose control with metformin on complications in overweight patients with type 2 diabetes (UKPDS 34). UK Prospective Diabetes Study (UKPDS) Group. Lancet 352(9131): 854-865

7. Brunzell JD, Robertson RP, Lerner RL, Hazzard WR, Ensinck JW, Bierman EL, Porte D Jr (1976) Relationships between fasting plasma glucose levels and insulin secretion during intravenous glucose tolerance tests. J Clin Endocrinol Metab 42(2):222-229

8. Pistrosch F, Schaper F, Passauer J, Koehler C, Bornstein SR, Hanefeld M (2009) Effects of the alpha glucosidase inhibitor acarbose on endothelial function after a mixed meal in newly diagnosed type 2 diabetes. Horm Metab Res 41(2):104-108

9. Ilkova H, Glaser B, Tunckale A, Bagriacik N, Cerasi E (1997) Induction of long-term glycemic control in newly diagnosed type 2 diabetic patients by transient intensive insulin treatment. Diabetes Care 20(9):1353-1356

10. Weng J, Li Y, Xu W, Shi L, Zhang Q, Zhu D, Hu Y, Zhou Z, Yan X, Tian H, Ran X, Luo Z, Xian J, Yan L, Li F, Zeng L, Chen Y, Yang L, Yan S, Liu J, Li M, Fu Z, Cheng H (2008) Effect of intensive insulin therapy on beta-cell function and glycaemic control in patients with newly diagnosed type 2 diabetes: a multicentre randomised parallel-group trial. Lancet 371(9626): 1753-1760

11. The ORIGIN Trial Investigators (2012) Basal insulin and cardiovascular and other outcomes in dysglycemia. N Engl J Med 367(4):319-328

12. Baxter MA (2008) The role of new basal insulin analogues in the initiation and optimisation of insulin therapy in type 2 diabetes. Acta Diabetol 45(4):253-268

13. Papa G, Baratta R, Cali V, Degano C, Iurato MP, Licciardello C, Maiorana R, Finocchiaro C (2012) Factors that influence basal insulin requirement in type 2 diabetes. Acta Diabetol 49(5): 387-393

14. Avogaro A, Schernthaner G (2012) Achieving glycemic control in patients with type 2 diabetes and renal impairment. Acta Diabetol. doi:10.1007/s00592-012-0442-x

15. Riddle MC, Rosenstock J, Gerich J (2003) The treat-to-target trial: randomized addition of glargine or human NPH insulin to oral therapy of type 2 diabetic patients. Diabetes Care 26(11): 3080-3086

16. Stirban A, Nandrean S, Gotting C, Tamler R, Pop A, Negrean M, Gawlowski T, Stratmann B, Tschoepe D (2010) Effects of n-3 fatty acids on macro- and microvascular function in subjects with type 2 diabetes mellitus. Am J Clin Nutr 91(3):808-813

17. Cusi K, Cunningham GR, Comstock JP (1995) Safety and efficacy of normalizing fasting glucose with bedtime NPH insulin alone in NIDDM. Diabetes Care 18(6):843-851

18. Pennartz C, Schenker N, Menge BA, Schmidt WE, Nauck MA, Meier JJ (2011) Chronic reduction of fasting glycemia with insulin glargine improves first- and second-phase insulin secretion in patients with type 2 diabetes. Diabetes Care 34(9):20482053

19. Alvarsson M, Sundkvist G, Lager I, Henricsson M, Berntorp K, Fernqvist-Forbes E, Steen L, Westermark G, Westermark P, Orn T, Grill V (2003) Beneficial effects of insulin versus sulphonylurea on insulin secretion and metabolic control in recently diagnosed type 2 diabetic patients. Diabetes Care 26(8):22312237

20. Wajchenberg BL (2007) Beta-cell failure in diabetes and preservation by clinical treatment. Endocr Rev 28(2):187-218

21. Laedtke T, Kjems L, Porksen N, Schmitz O, Veldhuis J, Kao PC, Butler PC (2000) Overnight inhibition of insulin secretion restores pulsatility and proinsulin/insulin ratio in type 2 diabetes. Am J Physiol Endocrinol Metab 279(3):E520-E528

22. Ceriello A, Motz E (2004) Is oxidative stress the pathogenic mechanism underlying insulin resistance, diabetes, and cardiovascular disease? The common soil hypothesis revisited. Arterioscler Thromb Vasc Biol 24(5):816-823

23. Prentki M, Nolan CJ (2006) Islet beta cell failure in type 2 diabetes. J Clin Invest 116(7):1802-1812

24. van Haeften TW, Twickler TB (2004) Insulin-like growth factors and pancreas beta cells. Eur J Clin Invest 34(4):249-255

25. Muniyappa R, Montagnani M, Koh KK, Quon MJ (2007) Cardiovascular actions of insulin. Endocr Rev 28(5):463-491

26. Forst T, Hohberg C, Pfutzner A (2009) Cardiovascular effects of disturbed insulin activity in metabolic syndrome and in type 2 diabetic patients. Horm Metab Res 41(2):123-131

27. Binggeli C, Spieker LE, Corti R, Sudano I, Stojanovic V, Hayoz D, Luscher TF, Noll G (2003) Statins enhance postischemic hyperemia in the skin circulation of hypercholesterolemic patients: a monitoring test of endothelial dysfunction for clinical practice? J Am Coll Cardiol 42(1):71-77

28. Hansell J, Henareh L, Agewall S, Norman M (2004) Non-invasive assessment of endothelial function-relation between vasodilatory responses in skin microcirculation and brachial artery. Clin Physiol Funct Imaging 24(6):317-322

29. Pistrosch F, Passauer J, Fischer S, Fuecker K, Hanefeld M, Gross P (2004) In type 2 diabetes, rosiglitazone therapy for insulin resistance ameliorates endothelial dysfunction independent of glucose control. Diabetes Care 27(2):484-490

30. Yki-Jarvinen H, Utriainen T (1998) Insulin-induced vasodilatation: physiology or pharmacology? Diabetologia 41(4):369-379

31. Agarwal N, Rice SP, Bolusani H, Luzio SD, Dunseath G, Ludgate M, Rees DA (2010) Metformin reduces arterial stiffness and improves endothelial function in young women with polycystic ovary syndrome: a randomized, placebo-controlled, crossover trial. J Clin Endocrinol Metab 95(2):722-730 
32. Fidan E, Onder EH, Yilmaz M, Yilmaz H, Kocak M, Karahan C, Erem C (2011) The effects of rosiglitazone and metformin on inflammation and endothelial dysfunction in patients with type 2 diabetes mellitus. Acta Diabetol 48(4):297-302

33. Monnier L, Mas E, Ginet C, Michel F, Villon L, Cristol JP, Colette C (2006) Activation of oxidative stress by acute glucose fluctuations compared with sustained chronic hyperglycemia in patients with type 2 diabetes. JAMA 295(14): $1681-1687$

34. Wang J, Alexanian A, Ying R, Kizhakekuttu TJ, Dharmashankar K, Vasquez-Vivar J, Gutterman DD, Widlansky ME (2012) Acute exposure to low glucose rapidly induces endothelial dysfunction and mitochondrial oxidative stress: role for AMP kinase. Arterioscler Thromb Vasc Biol 32(3):712-720
35. Williams SB, Goldfine AB, Timimi FK, Ting HH, Roddy MA, Simonson DC, Creager MA (1998) Acute hyperglycemia attenuates endothelium-dependent vasodilation in humans in vivo. Circulation 97(17):1695-1701

36. Hanefeld M, Koehler C, Hoffmann C, Wilhelm K, Kamke W, Gerstein H (2010) Effect of targeting normal fasting glucose levels with basal insulin glargine on glycaemic variability and risk of hypoglycaemia: a randomized, controlled study in patients with early type 2 diabetes. Diabet Med 27(2):175-180

37. Marbury TC, Schwartz S, Rosenberg MA, Jariwala N, Becker RH, Johnston PS (2008) A pilot study to examine the feasibility of insulin glargine in subjects with impaired fasting glucose, impaired glucose tolerance or new-onset type 2 diabetes. Exp Clin Endocrinol Diabetes 116(5):282-288 